\title{
Importance of catalpa groups in cultural city greening in the case of Uzbekistan
}

\author{
$B$ Kurbaniyazov ${ }^{1, *}, G$ Berdimuratov ${ }^{2}, S H$ Kholova $^{3}, A$ Safarov ${ }^{4}$, and $K$ Safarov $^{4}$ \\ ${ }^{1}$ Karakalpakstan State University, Nukus, Republic of Karakalpakstan, Uzbekistan \\ ${ }^{2}$ Aral Sea International Innovation Center under the President of the Republic of Uzbekistan, \\ Tashkent, Uzbekistan \\ ${ }^{3}$ Tashkent State Agrarian University, Kibray district, Tashkent province, Uzbekistan \\ ${ }^{4}$ National University of Uzbekistan named after Mirzo Ulugbek, Tashkent, Uzbekistan
}

\begin{abstract}
The catalpa tree is a member of the family Bignoniaceae, a species of catalpa. Representatives of this family consist of trees, shrubs, lianas and grasses, and are distinguished from other members of the family by their ornamental flowers and unusual leaves. There are regions with different climatic conditions, and in the soil and climatic conditions of the experimental cities of Tashkent and Nukus in Uzbekistan, it is important to select the composition of tree species resistant to various environmental factors. In the soil and climatic conditions of different regions of Uzbekistan, along with ornamental native plants, the widespread use of tree species introduced to our country will certainly bear fruit. The results of the study show that the use of Catalpa species in landscaping should take into account their bioecological properties. In Tashkent, the Catalpa speciosa Walder ex Engelm can be widely recommended for semi-shaded areas and in the soil-climatic conditions of Nukus for seedling breeding of Catalpa bignonioides Walt.
\end{abstract}

\section{Introduction}

The catalpa tree is a member of the family Bignoniaceae, a species of catalpa. Representatives of this family consist of trees, shrubs, lianas and grasses, and are distinguished from other members of the family by their ornamental flowers and unusual leaves $[1,2]$. The family consists of 100 genera and about 500 species and grows in tropical and subtropical climates. The family Catalpa is more common than other families of the family. It consists of 10 species, of which 5 species are widespread in the CIS countries [3].

The catalpa tree is a symbol of U.S. states such as Indiana, Kentucky and Tennessee. The tree is common in the U.S. state and southeast. They have very large massifs in the Ohio River Valley, the mountainous regions of North Carolina, Tennessee, Kentukki, and West Virginia. Catalpa tree has a wide geographical area and can grow to withstand different climatic conditions. The average summer temperature of the regions where the natural area of the catalpa tree is distributed is $21^{\circ} \mathrm{C}$ in the north, $27^{\circ} \mathrm{C}$ in the south, and the amount of precipitation is $760-1,300 \mathrm{~mm}$ [6].

* Corresponding author: b.kurbaniyazov@,yandex.com 
The wood of the catapult is white, light, extremely hard, does not rot in moisture, so it is used for sleepers and telegraph poles. Catalpa is as such plant, it is widely planted in parks and streets. In North America, it is found in areas where the Mississippi and Missouri rivers join the Ohio River, in the state of Tennessee, and in the western districts of Northern Arkansas $[10,11]$ and commonly occurs in urban parks of Uzbekistan. As it is a very ornamental tree, it is often planted in landscaping purposes.

Another scenic species of the genus is the Catalpa bignonioides Walt., Native to North America. It has been introduced by scientists of the Tashkent Botanical Garden in Tashkent and grows and reproduces very well. This species differs from the catapult in that it is partially short and vigorous, the leaves are sharply pointed, the flowers are small, the petals are thin, and the tree enters early flowering $[3,5,10,11]$.

A program of development measures for 2018-2020 has been developed for the unitary enterprise "Uzyolkokalamzorizatsiya" to ensure the implementation of the tasks set in the organization of departments for plant protection and beautification, coordination of green facilities.

In accordance with the program of landscaping and beautification of roads, city streets, it is planned to plant more than 1.6 million trees and shrubs along the roads, and 782,000 $(103,000$ of them in the capital) on city streets. In the program, plants such as pine, maple, oak, chestnut, ash, Indian nasturtium are shown as ornamental seedlings $[5,8]$.

In Uzbekistan, a great deal of work is being done to plant greenery and create a favorable infrastructure. Nowadays, along with the construction of tall buildings in Nukus, it is also recognized that the scale of green areas is increasing, which further enhances the beauty of the city.

It is known that the study of bioecological and landscape features of ornamental tree species introduced in accordance with the soil and climatic conditions of Uzbekistan is an urgent problem [9]. Trees and shrubs representing the flora not only change the appearance of the city with their landscape features, but also create a microclimate in the planted areas, clean the air, enhance the human mood, as well as give scenery and beauty to streets and squares, neighborhoods and residential areas $[5,6]$.

Green crops have not only aesthetic but also psychological significance. It can also be used as a plant protection, hedge or fence in the landscaping and beautification of sidewalks, areas adjacent to highways, taking into account the urban transport traffic in the design of tree planting. The convenience of trees for human beings shows how much they are connected with humanity and their importance in urban construction [7].

It is known that in our country there are regions with different climatic conditions, and in the soil and climatic conditions of the experimental cities of Tashkent and Nukus, it is important to select the composition of tree species resistant to various environmental factors.

Therefore, for urban landscaping, it is necessary to select and propagate introduced highly ornamental tree species that are resistant to various toxic gases emitted into the air by cars, extreme temperatures and cooling, as well as drought and soil salinity $[4,8]$.

\section{Materials and methods}

The objects of study were two species of the catalpa family - the catalpa (Catalpa speciosa Walder ex Engelm) and the bignonian catalpa (Catalpa bignonioides Walt).

In order to select the most optimal methods of generative and vegetative propagation of ornamental species of the Catalpa family and to recommend them for ornamental horticulture, experiments were conducted in Tashkent Botanical Garden and the International Aral Sea Innovation Center under the President of Uzbekistan on soil and 
climatic conditions. Phenological observations were made according to the methodology of G F Gizatullina [4].

Propagation of the studied plants from seeds, treatment with stimulants before sowing in seeds, and biometric measurements were performed using generally accepted methods [8, $10,11]$.

\section{Results and discussion}

Phenological observations are important in the study of plant growth and development, helping to determine the durations of different phases, the impact of environmental factors on plant development, and changes in plants.

According to biometric measurements conducted in Tashkent, the Catalpa speciosa Walder ex Engelm tree grows up to 20 meters in height (some species are 25 meters), 0.4 meters in diameter. and the trees were found to be large trees up to $8 \mathrm{~m}$ in height and 0.25 $\mathrm{m}$ in diameter. In both regions, the trunk was erect, the branches were pyramidal, the bark of the trunk and branches was reddish-brown, and the neck was cracked.

The leaves of the tree are rectangular, up to $15-20 \mathrm{~cm}$ wide and 20-30 cm long, simple, arranged in a row on a branch, and belong to the type of large-leaved trees. At the time of observation, it was noted that the size of some leaves was very large, which is due to the large size of the leaves - the leaves of seedlings stored in conditions of soil fertility and relative humidity of 2-3.5 years, up to $26-27 \mathrm{~cm}$ in width and $21-22 \mathrm{~cm}$ in height. the band was found to be between $10-11 \mathrm{~cm}$. The leaves are broad, large, oval, sometimes elongated, reaching $15-30 \mathrm{~cm}$ in height, the tip is sharp. The face is bright green, the hairless back is hard, and odorless. The length of the leaf band is 10-15 cm (Fig. 1).

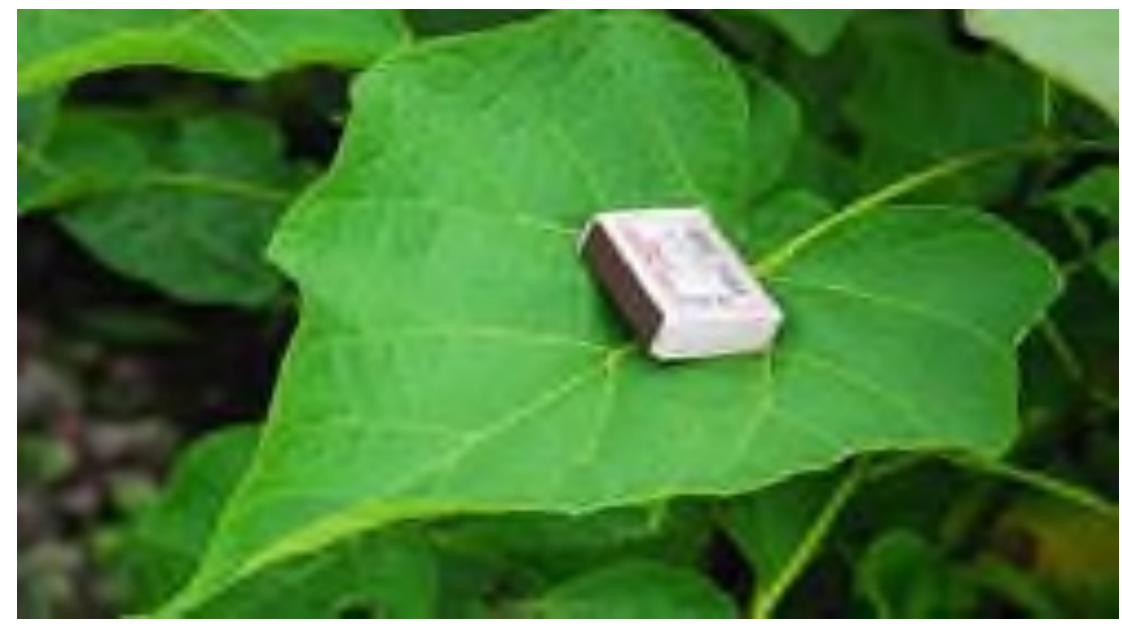

Fig. 1. Appearance of a catalpa (Catalpa speciosa Walder ex Engelm) tree leaf.

The flowers are funnel-shaped, $3.5-5 \mathrm{~cm}$ in size, white, the base of the flower is yellow, small brown spots are scattered at the base of the flower. The flowers are collected in the form of inflorescences on the stem, reaching a length of 15-30 cm (Fig. 2). 


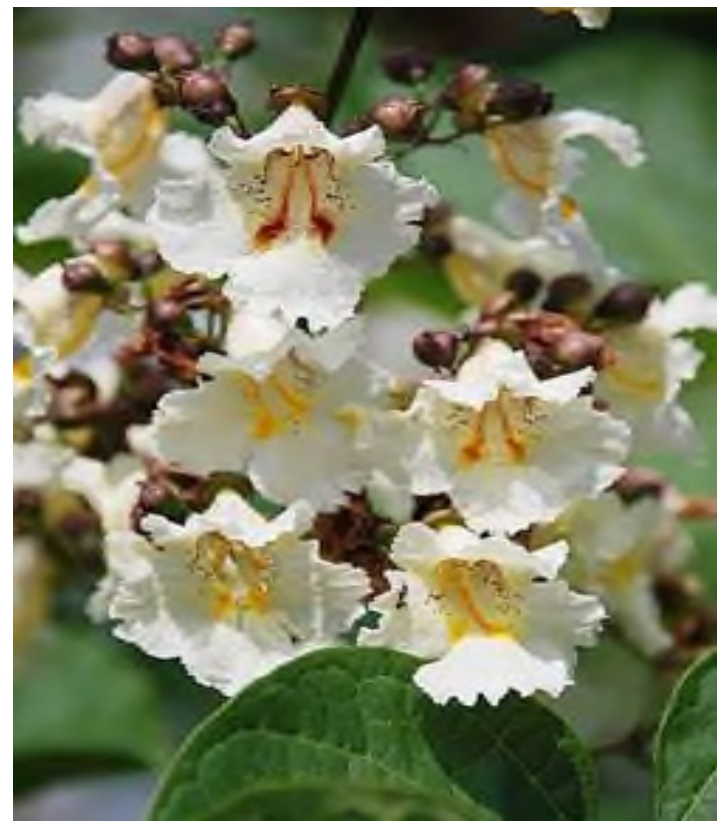

Fig. 2. Appearance of a catalpa (Catalpa speciosa Walder ex Engelm) tree flower.

The fruits are in the form of long cones, their length is $25-40 \mathrm{~cm}$, width $1.5 \mathrm{~cm}$, the skin is thick, and brown. The berries are stored in the tree even in the first days of spring. After the rainy days begin, the fruit splits in two and the seeds are scattered around. As a result of the observations, a natural reproduction of the seeds of the catalpa tree was observed in Tashkent, while no natural increase of the seeds of this tree was observed in the soilclimatic conditions of Nukus.

The color of the seeds was light brown, flat, hairy and winged, and a total of 90 to 150 seeds were found in the pods, with an average of $116 \pm 4.52$ seeds. 1 seed was $2.5 \pm 0.12$ $\mathrm{cm}$ long and $0.55 \pm 0.01 \mathrm{~cm}$ wide (Fig. 3). The weight of 1,000 seeds is $20-24 \mathrm{~g}$, and $1 \mathrm{~kg}$ of seeds contains an average of 40-45,000 seeds. The seeds of this tree do not lose their forgetfulness for up to three years. Seeds collected for planting and propagation are stored in paper or cloth bags [9].

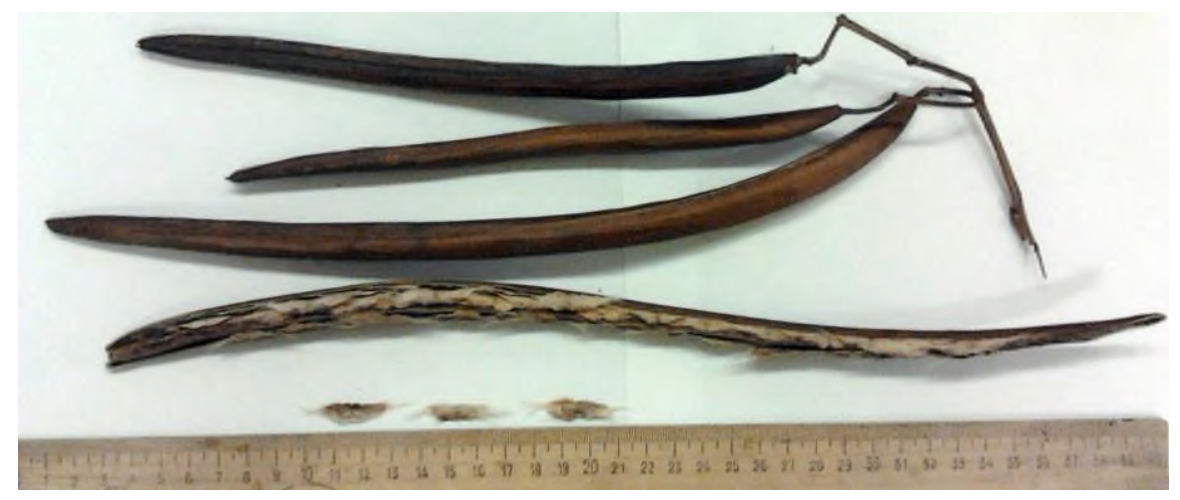

Fig. 3. Appearance of a catalpa (Catalpa speciosa Walder ex Engelm) tree fruit.

The seeds of this tree are propagated in early spring by soaking in warm water for 2 days and sprinkling on specially prepared furrows in a well-agronomically treated, heated 
soil area. When propagated for experimentation in small areas, tree seeds are propagated by sowing seeds on special $1.5-2 \mathrm{~m}$ sized floors.

Propagation of the catalpa tree in Tashkent conditions was carried out in the spring in the Tashkent Botanical Garden. In order to make the experimental result more effective, the seeds were sown in 2 different variants, i.e. in the shade and semi-shade area, sorted by 100 pieces and in 4 replications. The substrate was prepared from peat, soil, sand (in the ratio $1 \times 1 \times 1)$, planted on small floors, followed by observation.

In the first option (shade area): $80 \%$ of seeds germinate after 10-14 days, but $75 \%$ of germinated seedlings wither after 1.5 months. For this reason, it has been found that propagating catalpa trees from seed in the shade area is not effective.

In the second option (semi-shaded area): seeds germinate $85 \%$ after 9-12 days. Followup work was carried out continuously every 10 days and was recorded in the phenocathection book. The total height of a 20 -day-old plant is $10-11 \mathrm{~cm}$, the root length is $5-6 \mathrm{~cm}$ and the number of leaves is 3-5, the height of 30-35-day-old seedlings is $16-17 \mathrm{~cm}$, the length of the roots is $10-16 \mathrm{~cm}$ and the number of leaves is 7-8. In the growing season, it was observed that the average height of seedlings irrigated with various stimulants was 120-150 cm (Fig. 4).

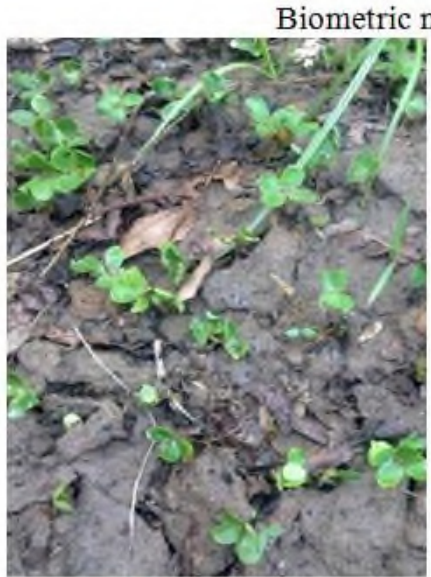

May 12,2019

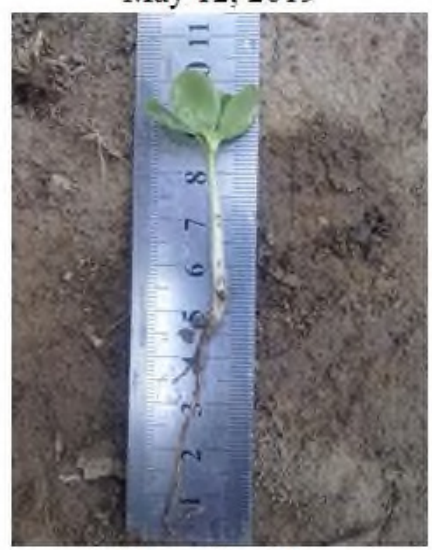

May 27,2019

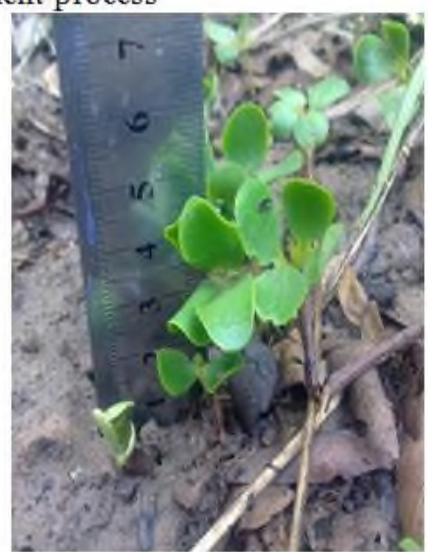

May 20,2019

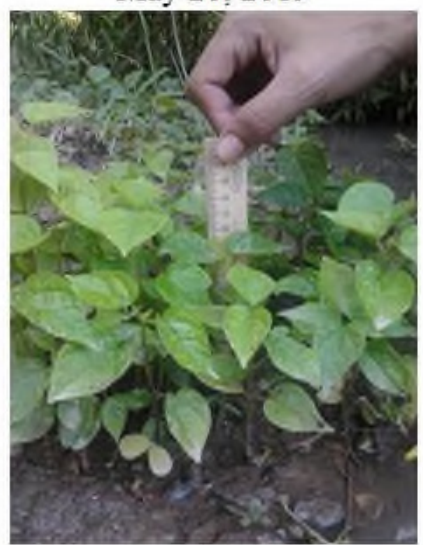

June 8, 2019

Fig. 4. Experience in propagating the seeds of the catalpa (Catalpa speciosa Walder ex Engelm).

At the end of the experiments, it was found that the propagation of Catalpa speciosa Walder ex Engelm from seed in Tashkent option 2 (semi-shade zone) was effective. 
In order to propagate the plant Catalpa bignonioides Walt in different soil and climatic conditions and to conduct its biometric measurements, in 2019 on the territory of the International Aral Sea Innovation Center under the President of the Republic of Uzbekistan was observed bignonia catalpa. In 2019, the height of seedlings reached $140 \mathrm{~cm}$, and in the body of the plant grew 3 branches. At the end of the growing season, the number of leaves on the 1 st branch of the plant body was 13 , the number of leaves on the second branch was 20 , and the number of leaves on the third branch was 21 . The total number of leaves was 44, the average length of the leaves was $18 \mathrm{~cm}$ and the width was $15 \mathrm{~cm}$ (Table 1).

Table 1. Biometric measurements of Catalpa bignonioides Walt, planted in 2019 on the territory of the International Aral Sea Innovation Center under the President of the Republic of Uzbekistan

\begin{tabular}{|c|c|c|c|c|}
\hline $\begin{array}{c}\text { Catalpa } \\
\text { variety }\end{array}$ & $\begin{array}{c}\text { Height, } \\
\text { cm }\end{array}$ & $\begin{array}{c}\text { No. of branches and } \\
\text { their length, cm }\end{array}$ & $\begin{array}{c}\text { No. of } \\
\text { leaves }\end{array}$ & $\begin{array}{c}\text { Leaf length/width, } \\
\text { cm }\end{array}$ \\
\hline $\begin{array}{c}\text { Catalpa } \\
\text { bignonioides } \\
\text { Walt }\end{array}$ & 140 & $\begin{array}{c}3 \text { branches: } \\
\text { first branch }-13 \text { leaves; } \\
\text { second branch }-20 \\
\text { leaves; } \\
\text { third bramch }-21 \\
\text { leaves. }\end{array}$ & 44 & $18 / 15$ \\
\hline
\end{tabular}

In order to determine the bioecological properties of another ornamental species of the category, Catalpa bignonioides Walt, planted in the International Aral Sea Innovation Center under the President of the Republic of Uzbekistan, Bignonia catalpa was planted on Beruni Street in Nukus. The tree was distinguished from other tree species by its landscape, the size of its leaves, the appearance of its flowers, and the unique appearance of its berries.

There are a total of 221 tree plants on Beruni Street in Tashkent selected as the experimental area, of which 111 bushes or 50\% are Bignonia catalpa (Catalpa bignonioides Walt). The height of Bignonia catalpa (Catalpa bignonioides Walt) in Nukus city is on average 2.5-2.8 $\mathrm{m}$ in soil-climatic conditions, with a large number of branches. According to the results of the study, the average length of the leaves was $26.5 \mathrm{~cm}$, the average width was $16.5 \mathrm{~cm}$, and the average length of the leaf blade was $14.5 \mathrm{~cm}$ (Table 2).

Table 2. Biological characteristics of Catalpa bignonioides Walt

\begin{tabular}{|c|l|c|c|}
\hline$\#$ & Biological charactiersitics & Size & $\begin{array}{c}\text { Date of } \\
\text { observation }\end{array}$ \\
\hline 1 & Height, m & $2-2.8$ & 2020 \\
\hline 2 & Initial stages of leaf, cm & $2-3$ & April 10, 2020 \\
\hline 3 & Leaf-stem length, cm & 14 & \\
& Leaf length, cm & 26,5 & April 17, 2020 \\
& Leaf width, cm & 16,5 & \\
\hline 4 & Flower buds, cm & $0,5-1$ & April 25, 2020 \\
\hline 5 & Blooms, cm & $2,5-3,5$ & May 10, 2020 \\
\hline & Mature blooms, cm & $3,5-4$ & May 24, 2020 \\
\hline 6 & Flower-stem length, cm & $10-12$. & May 25, 2020 \\
& No. of flowers on a branch & $20-50$ & 2020 \\
\hline 7 & Fruit length, cm & $8-10$ & \\
\hline
\end{tabular}

\section{Conclusions}

In the soil and climatic conditions of different regions of Uzbekistan, along with ornamental native plants, the widespread use of tree species introduced to our country will certainly bear fruit. The results of the study show that the use of Catalpa species in landscaping should take into account their bioecological properties. In Tashkent, the 
Catalpa speciosa Walder ex Engelm can be widely recommended for semi-shaded areas and in the soil-climatic conditions of Nukus for seedling breeding of Catalpa bignonioides Walt.

\section{References}

1. R. T. Olsen, J. H. Kirkbride, Brittonia, 69(3), 387-421 (2017)

2. A. S. Berdimuratovna, S. Kozhaakhmetov, An International Multidisciplinary Research Journal, 10(7), 311-315 (2020)

3. T. Hazra, M. Hazra, S. Bera, M. Khan, Journal of the Geological Society of India, 97(3), 267-270 (2021)

4. B. Alikhanov, S. Alikhanova, R. Oymatov, Z. Fayzullaev, A. Pulatov, IOP Conference Series: Materials Science and Engineering, 883(1), 012088 (2020)

5. A. Kayimov, E. Berdiev, Dendrology, 305 (2009)

6. A. Kayimov, J. Turok, Science and Technology, 124 (2012)

7. V. Pechenitsyn, A. Azamov, Cultural City Greening, 28 (2005)

8. Y. Gafforov, R. Phookamsak, H. -B. Jiang, D. N. Wanasinghe, M. Juliev, Botany, 97(12), 671-680 (2019)

9. S. Isaev, S. Khasanov, Y. Ashirov, A. Gofirov, T. Karabaeva, In E3S Web of Conferences, 244, 02047 (2021)

10. M. A. Dirr, Stipes Publishing, 552 (1990)

11. N. Robinson, Routledge, 353 (2016) 